\title{
A Novel Wideband RDRA for WBAN Applications
}

\author{
Ekta Bhayana, Svav Prasad, Parikshit Vasisht, Moin Uddin, Taruna Sharma, Sudhakar Ranjan
}

\begin{abstract}
A Wideband Rectangular Dielectric Resonator Antenna (RDRA) is presented in this manuscript. The proposed RDRA is designed for wideband body area network (WBAN) applications due to its compact size and wideband characteristics. The proposed antenna can be effectively integrated with modern medical devices for transmitting biological signals. WBAN attract variety of applications in monitoring human health in the domains such as sports, entertainment, defense, and healthcare industry. This manuscript presents a novel RDRA to meet recent research challenges as well as applications for future generation wideband RF-device technology for BANs. The miniaturized RDRA Antenna is designed for biotelemetry using HFSS 13, FEM based 3D EM Simulation Software.
\end{abstract}

Keywords: Rectangular Dielectric Resonator Antenna (RDRA), WBAN (wireless body area network), Reflection coefficient, DGS (defective ground structure).

\section{INTRODUCTION}

Body Area Networks (BANs) connect together nodes attached to a human body and transfer the data to an external infrastructure. The wireless communication channel and a variety of miniature sensor devices have lead to many useful applications of BANs, such as healthcare monitoring, military and emergency coordination, rescue services, sports, and entertainment. Recently with the emerging demand of WBAN systems, wideband/UWB communication technology is widely used with enhanced accuracy. This technology is robust in providing energy efficient transmission of biological data and signals through wireless BAN. WBAN devices offer a high degree of freedom in terms of installation such as they may be embedded type (inside the body), implants, or may be surface mounted in any fixed position on the body. This technology is portable due to its compact size and large bandwidth thereby enabling humans to carry with ease in different positions, in clothes pockets, by hand or in various bags.

Manuscript received on April 07, 2021.

Revised Manuscript received on April 16, 2021.

Manuscript published on April 30, 2021.

* Correspondence Author

Ekta Bhayana, Department of Electronics and Communication, Lingaya's Vidyapeeth, Faridabad, India.

Dr. Svav Prasad, Department of Electronics and Communication, Lingaya's Vidyapeeth, Faridabad, India.

Parikshit Vasisht*, School of Engineering and Technology, Sohna, GuruGram, Haryana, India.

Moin Uddin, School of Engineering and Technology, Sohna, GuruGram

Taruna Sharma, J.C. Bose university of Science and Technology

Sudhakar Ranjan, School of Engineering and Technology, Sohna, GuruGram, Haryana, India.

(C) The Authors. Published by Blue Eyes Intelligence Engineering and Sciences Publication (BEIESP). This is an open access article under the CC BY-NC-ND license (http://creativecommons.org/licenses/by-nc-nd/4.0/) light-weightiness, temperature stability, cost effectiveness as well as ease of fabrication [1]. RDRAs generally have The rapid development of wearable computing systems is driving a need for suitable body antennas. The proposed RDRA is a proficient support for WBAN technology by virtue of its physical compactness, higher radiation efficiency $(\eta)$,due to the absence of conductors from the edges of the radiator.Subsequently, the DRAs also support different coupling mechanisms such as coaxial line probe, coplanar waveguide[CPW], micro-strip slot coupling, strip line coupling, aperture slot coupling, along with dielectric image guide method pin more features to it $[2,3]$. In addition, a novel feeding mechanism for wideband application RDRA was also depicted in [4].The manuscript presents a wideband surface mount/on-body RDRA for wireless body area network applications. The proposed antenna has a maximum radiation normal to the humanbody surface for communication with implanted devices in the $5.8 \mathrm{GHz}$ industrial, scientific, and medical (ISM) band. In addition, to transmit the biological information received from the implanted devices to other on-body devices, the proposed antenna was designed to have a monopole-like radiation pattern along the surface of the human body for communication in the $2.45 \mathrm{GHz}$ ISM band. The antenna was fabricated, and its performance was measured by attaching it to a human-equivalent semisolid phantom. In addition, the human-body effect was studied to ensure antenna performance under an actual situation.Manuscript Presents, the multimode RDRA is designed for improved frequency response with high precision for modern day's wireless applications like LTE, Wi-MAX, WLAN. The Defective Ground Structure is incorporated in the ground plane in proposed rectangular dielectric resonator antenna along with spiral shaped DGS with rectangular edges. The dielectric material foam of permittivity9.8(alumina ceramic) with 3 modes of dielectric resonator antenna excited are precisely useful for the wireless telephony, mobile cellular communication and wireless sensor networks etc. It is also compatible with advance circuitry.

\section{GEOMETRY AND DESIGNING}

Fig.1. demonstrate the configuration of the projected antenna of Multi mode RDRA. In this geometry, a substrate of $100 \mathrm{~mm} 2$ has a height of $1.6 \mathrm{~mm}$ and the dimensions of ground plane are $57 \mathrm{~mm} \times 100 \mathrm{~mm} \times 0.018 \mathrm{~mm}$. The ground plane is above the substrateof FR4 epoxy having a relative permittivity of 4.4. The rectangular DRA is made up of alumina ceramichaving the relative permittivity of 9.8 and the dimension for the same is $24 \mathrm{~mm}$ X20mm X30 mm. The antenna feed employed is strip line feed.

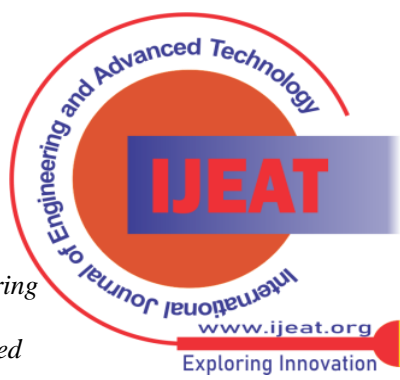



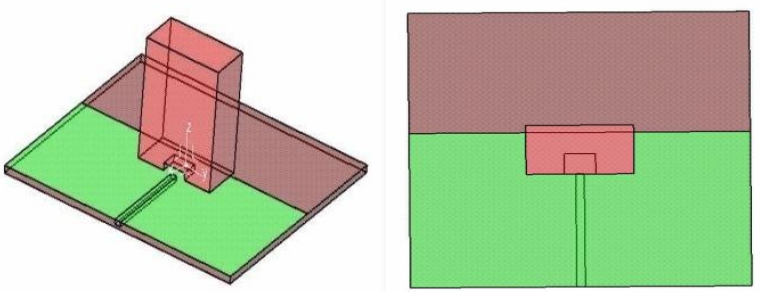

Fig1. Geometrical configuration of RDRA with DGS

Fig.2. shows the geometrical aspects of the designed antenna. As shown in figure, The Defective Ground Structure is incorporated in the ground plane along with spiral shaped DGS with rectangular edges. DGS of spiral shape consists of dimensions $m=28 \mathrm{~mm}, \mathrm{n}=12 \mathrm{~mm}, \mathrm{c}=12 \mathrm{~mm}, \mathrm{~d}=9 \mathrm{~mm}, \mathrm{e}=7 \mathrm{~mm}$, $\mathrm{f}=7 \mathrm{~mm}, \mathrm{~g}=3 \mathrm{~mm}, \mathrm{j}=3 \mathrm{~mm}, \mathrm{k}=4 \mathrm{~mm}$ respectively.
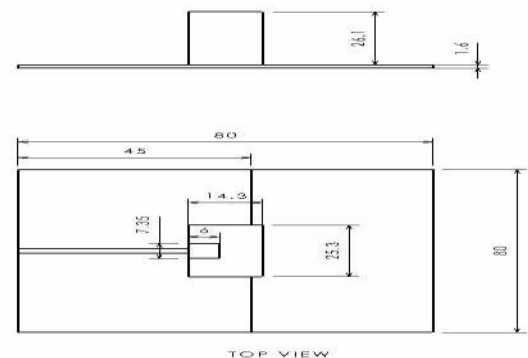

Fig 2. Shows the 2d view Diemsions of RDRA

\section{RESULTS AND DISCUSSION}

- The frequency response with a bandwidth of $21.6 \%$ is achieved at the frequency range between $2.6 \mathrm{GHz}$ and $5.1 \mathrm{GHz}$ with a peak gain of $4.5 \mathrm{~dB}$ and peak directivity of 4.98dBi.

- Fig.3. the broadband radiation pattern is achieved as S11 Parameter of optimized DGS with partial ground. The different modes are excited within the frequency range. The different modes are excited within $2.6 \mathrm{GHz}$ to 2.8GHz, $3.5 \mathrm{GHz}$ to $3.8 \mathrm{GHz}$ and $4.81 \mathrm{GHz}$ to $5.18 \mathrm{GHz}$ with resonant frequencies of $2.84 \mathrm{GHz}, 3.7 \mathrm{Ghz}$ and 5.1Ghz respectively.

- Fig.4. shows the graph drawn between the reflection coefficient affecting the s11 frequency response of ground plane with/ without spiral shaped DGS in rectangular DRA. The good results are achieved at the optimized DGS with (Partial Ground).

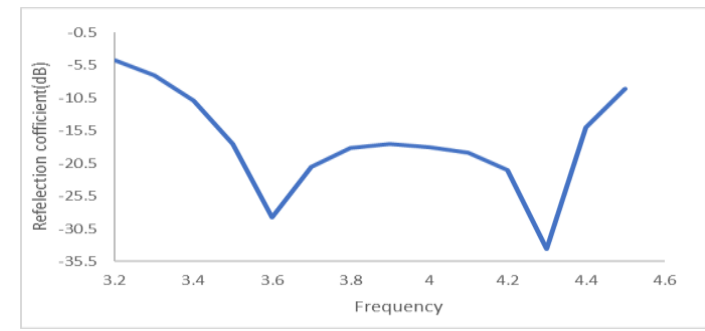

Fig.3. Shows S11 parameter optimized DGS with Partial Ground

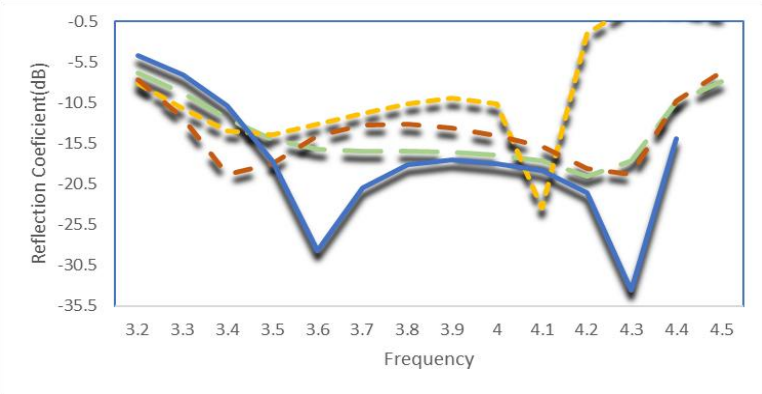

Fig.4. Shows reflection coefficient vs frequency with and without Partial/ full Ground with 3and 4 segment DGS

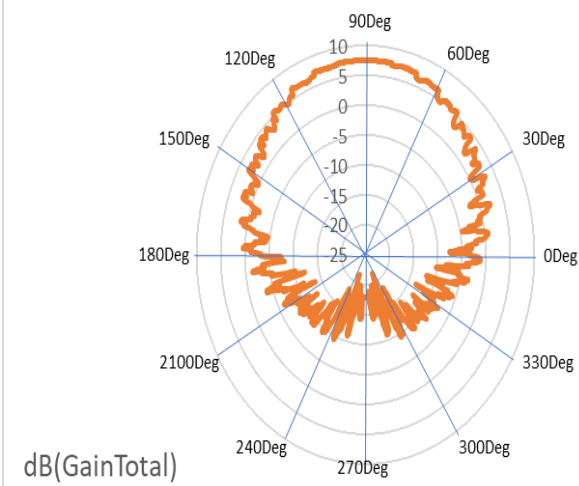

Fig.5. Shows 3D Polar Plot of optimized DGS with Partial Ground

- $\quad$ Fig.5. shows the lower 3d polar plot values to ensure lossless performance characteristics of antenna at a wide range of frequencies.

- $\quad$ Fig.6. shows the broadband radiation pattern is also achieved.

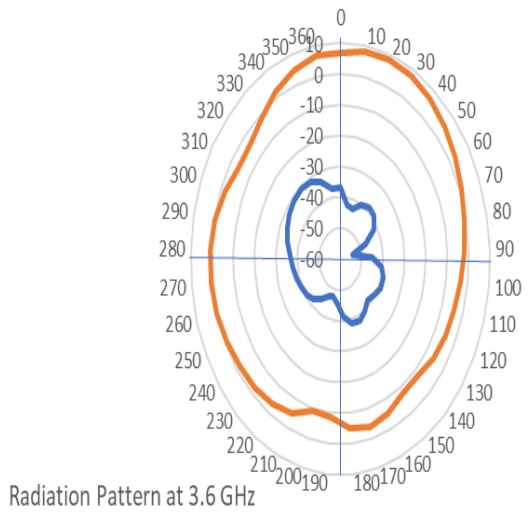

Fig.6. Shows Radiation Pattern at 3.6GHz of optimized DGS with Partial Ground

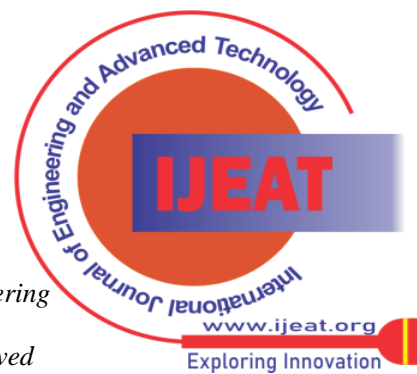




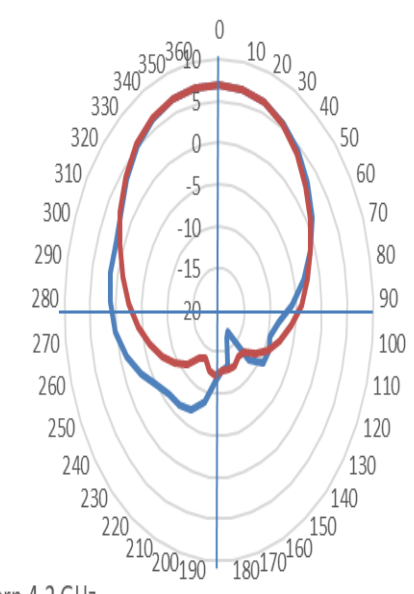

Radiation Pattern 4.2 GHz

Fig.6. Shows Radiation Pattern at 3.6GHz of optimized DGS with Partial Ground

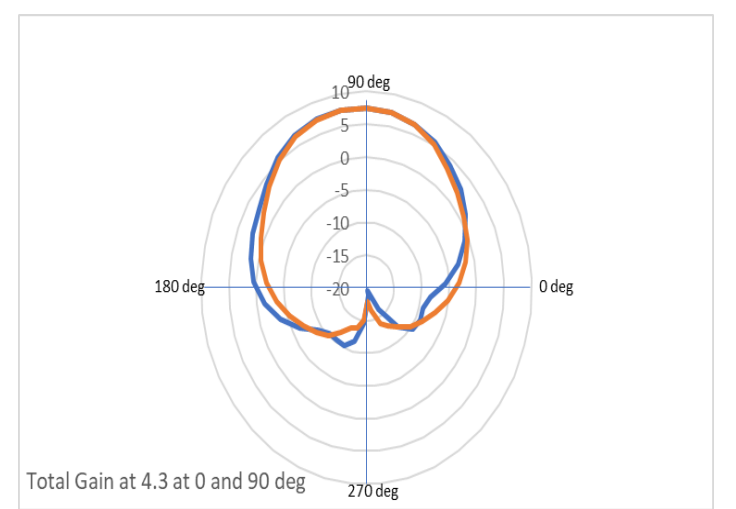

Fig.6. Shows Total Gain at 4.3 of optimized DGS with Partial Ground

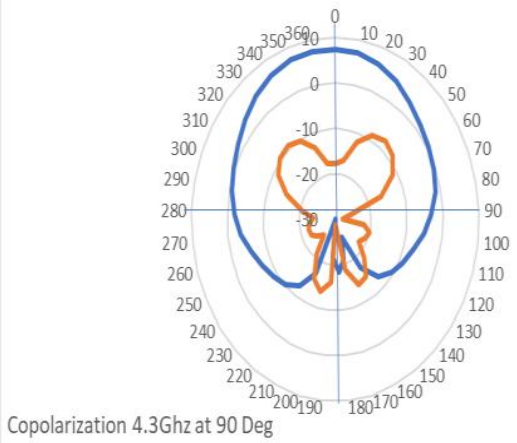

Fig.7. Shows Co-Polarization 4.3 of optimized DGS with Partial Ground

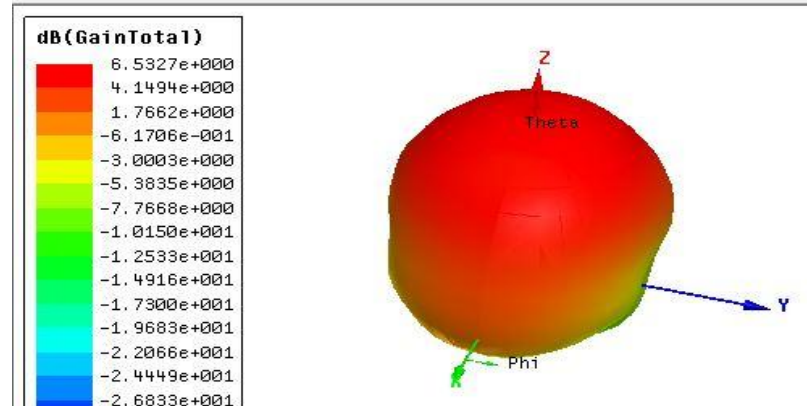

Fig.7. 3D Polar Plot

Retrieval Number: 100.1/ijeat.D24310410421
- Fig.7. shows the broadband radiation pattern of rectangular dielectric resonator antenna radiating at high gain with minimum losses is also achieved

\section{CONCLUSION}

The presented antenna is compact with a novel design and provides a high gain of $4.5 \mathrm{~dB}$ and a bandwidth of $21.6 \%$. The purpose of this antenna is to radiate in ISM Band and the desired result is achieved accordingly. The simulated results confirm the same with reflection coefficient and radiation parameter. The antenna is much useful in LTE, WLAN and Wi-MAX Applications.

\section{REFERENCES}

1. K.M. Luk, and K.W. Leung, Dielectric Resonator Antennas Handbook, Research Studies Press Ltd.,Baldock, Hertfordshire, England, 2003.

2. A. Petosa, Dielectric Resonator Antennas Handbook, Artech House Inc., 2007.

3. R.M. Baghaee, M.H. Neshati, and J.R. Mohassel, "Rigorous analysis of rectangular dielectric resonator antenna with an infinite ground plane", IEEE Transaction on Antenna and Propagation, Vol. 56, No. 9, September 2008

4. Varun Shukl, Arti Saxena, Swati Jain, "A NEW RECTANGULAR DIELECTRIC RESONATOR ANTENNA COMPATIBLE FOR MOBILE COMMUNICATION OR BROADBAND APPLICATIONS", Volume 3, Issue 2, July- September (2012), pp. 360-368 C IAEM

5. Uma Shankar Modani1, Gajanand Jagrawal2, "A SLOTTED ESHAPED STACKED LAYERS PATCH ANTENNA FOR 5.15-5.85 GHZ FREQUENCY BAND APPLICATIONS", International Journal of Electronics and Communication Engineering \& Technology (IJECET), ISSN 0976 - 6464(Print), ISSN 0976 - 6472(Online) Volume 4, Issue 3, May - June (2013), (C) IAEME

6. Deepika Pathak, Sudhir Kumar Sharma, Vivek Singh Kushwah, "Review Paper on Dual Band Dielectric ResonatorAntenna for Wireless ApplicationIndia International Journal (IJRASET) ISSN: 2321-9653; Volume 5 Issue XI November 2017.

7. Rose Basi, Glenn Rodrigues, Blaisey Soj, Vineet Suvarna, Naheed Anjum Khan " Design \& Implementation of a Multiband Antenna for Wireless Communication", Asian Journal of Convergence in Technology Volume IV Issue II ISSN NO: 2350-1146 I.F-5.1, 2015

8. Prof. Mrs. Kadam R. S., Mahadik Sonal Sudhir, Kadam Sneha Suresh, Khot Puja Ramchandra, "Design, simulation, optimization and fabrication of patch antenna by analyzing different shapes of Patch", Asian Journal of Convergence in Technology Volume IV, Issue I ISSN No.:2350-1146, I.F-5.1, 2015

9. Nilima A. Bodhaye, Research Scholar, Prasanna L. Zade, "Multi-band Double I-shaped slot Microstrip Patch Antenna With Defected Ground Structure for Wireless Application", Asian Journal of Convergence in Technology Volume IV Issue I ISSN NO: 2350-1146 I.F-5.11, 2015

10. Parikshit vasisht, N. Chattoraj, "Design and development of wideband RDRA FED with parallel conducting strips chamfered at edges separated by partial matching slab", 26 January 2017, https://doi.org/10.1002/mop.30375.

\section{AUTHOR PROFILE:}

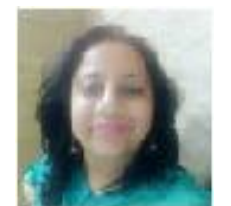

Ekta Bhayana, received her Diploma in Electronics and communication engineering from State Board of Technical Education Haryana, CHD in 1999. B.Tech in Electronics and communication from Lingaya's Institute of Management and Technology, Faridabad, Haryana, in 2004. M.Tech.

Published By: Blue Eyes Intelligence Engineering 


\section{A Novel Wideband RDRA for WBAN Applications}

in Digital Signal Processing from Linagay's Univerisity, Faridabad, Haryana, in 2009, and Pursuing Ph.D. in (Electronics \& Communication Engineering) Title "Design andDevelopment of wide band Rectangular Resonator Antenna for Wireless Communication Application", Lingaya's Vidyapeeth, Faridabad, Hrayana. Presently working as a Manager in Lumax Mannoh Allied Technology Ltd. IMT Manesar, Gurugram.She is having more than 13 years of experience in academia as well as in Industry.

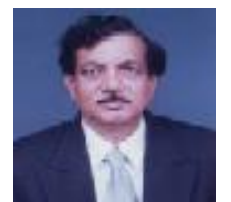

S.V.A.V. Prasad, as completed M.Tech, Ph.D. presently working as professor and Dean(academic affairs), Dean(R\&D), sir has developed various products like High voltage tester, VHF Wattmeter, standard signal, generator with $\mathrm{AM} / \mathrm{FM}$ modulator, wireless Becom, high power audio amplifier, wireless microphone and many more in the span of 25 years(1981-2007).sir has awarded for excellence in R\&D in year 1999,2004 and national quality award during the year 1999,2000,2004 and 2006.sir is fellow member of IEEE and life member of ISTE,IETE and society of audio\& video system. sir has published more than 155 papers in various national \& international conferences and journals, sir research area includes wireless communication, satellite communication \& acoustics, antenna, neural networks \& artificial intelligence. Reviewer for various national and international journals.

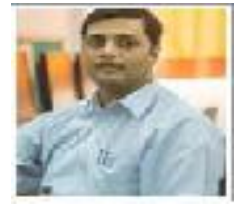

Dr. Parikshit Vasisht, working as a Controller of Examinations and Associate Professor in APEEJAY SATYA UNIVERSITY with a team of working in the higher education industry of over 20 years. Skilled in lecturing, Public Speaking, Science and Research. Strong education professional with B.Tech (ECE) has recently done his Ph.D from BIT Mesra, Ranchi (Jharkhand) in Antenna and Microwave Communications. He has published several research articles in reputed journals and International Conference.

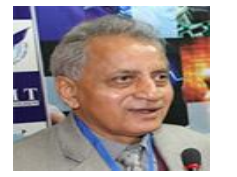

Prof. Moinuddin, is a former Pro-VC, Delhi Technical University and Former Dean, Faculty of Engineering, Jamia Hamdard. A member of several advisory committees, he advises on Science and Technology related pedagogy. He was also Director, Dr B.R. Ambedkar National Institute of Technology (NIT), Jalandhar, Punjab. Presently, he is working as distinguished professor in School of Engineering and Technology in Apeejay Stya University.

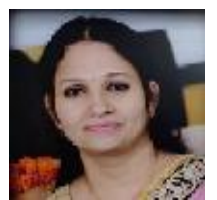

Taruna Sharma, (parashar.taruna@gmail.com) is an agile and innovative Ph.D scholar in Department of Electronics and Communication at J.C. Bose University of Science and Technology, YMCA, Faridabad, Haryana, India. Her qualification comprises of Diploma, B.E and M.Tech in Electronics and Communication. She has a keen interest in the field of RF Applications, Microwave \& RADAR Communication, Optics ,Graphene and related technologies. Her vision is to implement microwave and millimetre antenna technologies to eradicate societal problem.

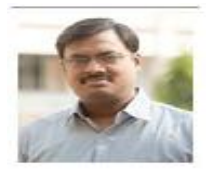

Dr. Sudhakar Ranjan, completed his Ph.D from YMCAUST, Faridabad 'A' Grade Accredited NAAC State Government University of Haryana. He did his M.Tech with distinction from YMCAIE, Faridabad. He has vast experience of 20 years in academia and industry. He is a professional in emerging technologies like Big Data, Hadoop \& Cloud Computing. His areas of research are in Hidden Web, Information Retrieval and Databases.

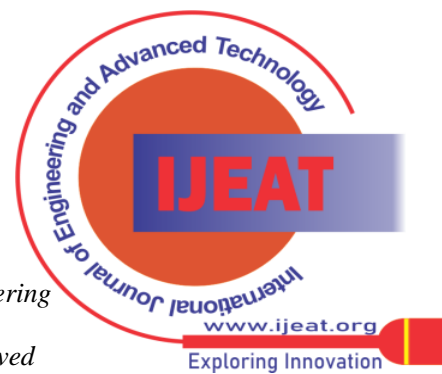

